(C) 2018 IEEE. Personal use of this material is permitted. Permission from IEEE must be obtained for all other uses, in any current or future media, including reprinting/republishing this material for advertising or promotional purposes, creating new collective works, for resale or redistribution to servers or lists, or reuse of any copyrighted component of this work in other works. 


\title{
An Equivalent Circuit Model for Predicting Core Loss in a Claw Pole Permanent Magnet Motor with Soft Magnetic Composite Core
}

\author{
Xin $\mathrm{Ba}^{1,2}$, Student Member, IEEE, Youguang $\mathrm{Guo}^{2}$, Senior Member, IEEE, Jianguo Zhu' ${ }^{2}$, Senior Member, IEEE, \\ Chengning Zhang ${ }^{1,3}$ \\ ${ }^{1}$ National Engineering Laboratory for Electric Vehicles, Beijing Institute of Technology, Beijing, 100081 China \\ ${ }^{2}$ Faculty of Engineering and Information Technology, University of Technology Sydney, NSW 2007 Australia \\ ${ }^{3}$ Collaborative Innovation Center for Electric Vehicles in Beijing, Beijing, 100081 China
}

\begin{abstract}
Soft magnetic composite (SMC) materials and SMC electromagnetic devices have attracted strong research interest in the past decades. However, SMC devices have large core loss, which needs to be put into consideration even at the design stage. Effective and accurate prediction of core loss becomes crucial for design and optimization of high-performance motors with these materials. Equivalent circuit model is a widely used method for machine analysis, due to the advantages in fast calculation with clear physical mechanism. This paper presents an equivalent circuit model to predict core losses of a claw pole permanent magnet motor with an SMC stator core. All the parameters including core loss resistance in the equivalent circuit model are identified based on finite element method to achieve high accuracy, and the effectiveness of the parameters identification method is experimentally verified. The proposed equivalent circuit model can predict core loss and motor's performance efficiently both in no-load and loading conditions.
\end{abstract}

Index Terms - Soft magnetic composite materials, claw pole motor, core loss, equivalent circuit model, finite element method.

\section{INTRODUCTION}

$\mathrm{S}$ oft magnetic composite (SMC) material is formed by surface-insulated iron powder particles, and possesses a number of advantages, including isotropic magnetic and thermal properties, low eddy current loss and relatively low total core loss at medium and higher frequencies, net-shape fabrication process with smooth surface and good finish, and prospect of very low cost mass production [1]. Due to its powder nature and isotropic magnetic property, SMC material is suitable for construction of electrical machines of threedimensional (3D) magnetic fluxes and complex structures, for which it is almost impossible or very difficult to use laminated steels. In the past decades, many investigations have been made to explore SMC material in different types of motor, such as claw pole motor [2], [3], transverse motor [4], [5], axial flux motor [6], [7], universal motor [8], [9] and so on. This paper will explore the equivalent circuit model for predicting core losses in a claw pole permanent magnet (PM) motor with SMC core.

There are three main types of loss in rotational electrical machines, namely the mechanical loss caused by the friction with air and between mechanical parts, the copper loss due to coil resistance, and the core loss caused by the variation of the magnetic flux in the core parts [10]. To be more specific, mechanical loss is related to the motor's rotating speed, and this is an uncontrollable component. In this research, we just discuss the electrical loss i.e. copper loss and core loss. The core loss can also be divided as three parts: hysteresis loss, eddy loss, and anomalous loss or excess loss. Generally, machines are designed for full-load operation where copper loss is dominant. Thus, core loss is usually neglected in equivalent circuit models [11]-[13]. However, core loss gradually takes the dominance in the total machine power loss as the load decreases. Moreover, core loss is crucial for highspeed motors because the core loss may be the dominant component of power loss when motors operate in high frequency. Therefore, core loss needs to be precisely calculated for high performance design and good control strategies.

Equivalent circuit model is a widely used method for electrical machine analysis, because it provides good analysis results with fast calculation. Generally, in equivalent circuit model, the total core loss including hysteresis loss, eddy loss and anomalous loss is modeled as one resistance in parallel with the magnetizing branch. According to the past publications, the major researches estimate the parameters of electrical machines including the equivalent core loss resistances from standard machine characterization tests, namely the DC test, no-load test and locked-rotor test [14][21]. A small part of researches estimate the core loss resistance from tedious mathematical formulation, and these methods more or less rely on experimental tests or with specific conditions [22], [23].

In this paper, the identification method which is based on finite element method (FEM) is applied to calculate the parameters of equivalent circuit model, without motor characterization tests. Moreover, it is well known that core loss is not only caused by the fundamental but also by the higher harmonics presented in the flux density. Another advantage of this method is to take harmonic components into account when calculating the core loss by summing up contributions from each order of harmonic. Thus, the proposed equivalent core loss resistance identification method can give a rather good estimation of the core loss in the claw pole permanent magnet (PM) motor with SMC core. In addition, compared with other core loss calculation methods, such as FEM, the main advantage of using an equivalent circuit model to predicting core loss is that it can provide results with fast 
calculation and clear physical mechanism. It is flexible with changing loading conditions changing and various operation conditions. Also, a comprehensive equivalent circuit model including core loss lays a solid foundation for advanced motor control strategies which help increase the efficiency of motor. Finally, the proposed equivalent circuit model can be easily extended to other similar machines.

\section{StRUCTURE AND Dimensions OF CLAW Pole PM Motor WITH SMC CORE}

In order to investigate the performance of the material, a PM claw pole SMC motor prototype was designed and fabricated at University of Technology Sydney in 2005 [24]. This motor is of the outer rotor structure, and the structure of the claw pole SMC motor is shown in Fig. 1. The outer rotor consists of a mild steel case, three arrays of $\mathrm{NdFeB}$ magnets for three phases, and two aluminum end plates. Since the flux density in the yoke is almost constant, mild steel is used for the construction of rotor. The stator has three stacks with an angular shift of 120 electrical degrees from each other. Each stator phase has two pieces of SMC claw pole discs and a single concentrated coil, which is housed between two claw pole discs.
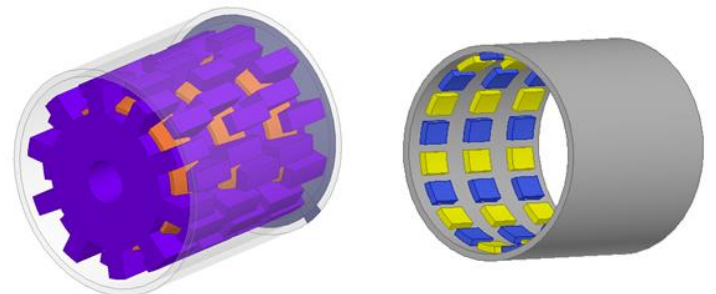

Fig. 1. The structure of the claw pole SMC motor

\section{Equivalent Circuit Model for PREDicting Core LOSSES IN STEADY-STATE CONDITIONS}

Using equivalent electric circuit is a common way to predict the motor performance in the area of electrical machine design and analysis. The machine is represented by lumped parameters such as rotational electromotive force (EMF), resistances and inductance. Taking phase $A$ as an example, the electrical circuit equation for per-phase of claw pole PM motor can be written by the Kirchhoff's voltage law as:

$$
v_{a}=R_{s} i_{a}+d \lambda_{a} / d t
$$

where $v_{a}$ and $i_{a}$ are the terminal voltage and phase current of the claw pole PM motor, $R_{s}$ is the stator winding resistance, and $\lambda_{a}$ the flux linkage of phase winding, which can be expressed in terms of the self and mutual inductances as following:

$$
\lambda_{a}=\lambda_{a a}+\lambda_{a b}+\lambda_{a c}+\lambda_{a f}=L_{a a} i_{a}+L_{a b} i_{b}+L_{a c} i_{c}+\lambda_{a f}
$$

where $L_{a a}$ is the self-inductance of stator winding, $L_{a b}$ and $L_{a c}$ are the mutual inductances of stator winings, and $\lambda_{a f}$ is the flux linkage generated by permanent magnets.
Because of the independent magic circuit of each stack in the claw pole PM motor, the mutual inductances between phase windings, $L_{a b}$ and $L_{a c}$, can be considered as zero. Furthermore, due to the small amount, the leakage inductance is also neglected in this analysis, so the above equation can be written as:

$$
\lambda_{a}=L_{a a} i_{a}+\lambda_{a f}=L_{s} i_{a}+\lambda_{a f}
$$

where $L_{s}=L_{a a}$ is known as the synchronous inductance of the claw pole PM motor.

Substituting the above expression of flux linkage into the circuit equation (1), one can obtain:

$$
v_{a}=R_{s} i_{a}+L_{s} \frac{d i_{a}}{d t}+\frac{d \lambda_{a f}}{d t}
$$

In steady state, (4) can be expressed in terms of voltage and current phasors as:

$$
\boldsymbol{V}_{\boldsymbol{a}}=\boldsymbol{E}_{\boldsymbol{a}}+\left(R_{s}+\mathrm{j} \omega L_{s}\right) \boldsymbol{I}_{\boldsymbol{a}}=\boldsymbol{E}_{\boldsymbol{a}}+\left(R_{s}+\mathrm{j} X_{s}\right) \boldsymbol{I}_{\boldsymbol{a}}
$$

where $X_{s}=\omega L_{s}$ is known as the synchronous reactance, $\boldsymbol{E}_{\boldsymbol{a}}$ the induced back EMF, and $\omega$ the angular frequency.

When running in synchronous mode, according to (5), the claw pole PM motor's steady-state performance for a singlephase can be predicted by the equivalent circuit model as shown in Fig. 2. In order to predict core loss, a core loss resistance $R_{c}$ is added, and the magnitude of core loss resistance does not remain constant within the operating frequency range. In the equivalent circuit model of electrical machine, the power consumed by the equivalent core loss resistance $R_{c}$ represents the core loss in core material, while the power consumed by the stator winding resistance $R_{s}$ simulates the copper loss of electrical machine. Although the general practice of mathematical model of core loss is to separate the total core loss into hysteresis loss, eddy loss, and anomalous loss or excess loss, in this proposed equivalent circuit model, the core loss is evaluated together and just one resistance is used to model the total core loss.

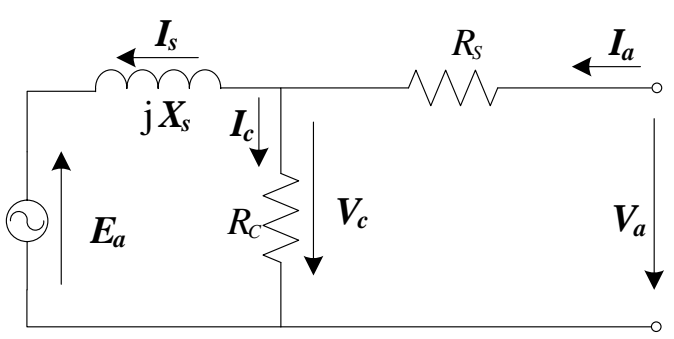

Fig. 2. Per-phase equivalent circuit including core losses

\section{PARAMETERS IDENTIFICATION OF EQUIVALENT ELECTRIC CIRCUIT}

\section{A. 3-D Magnetic Field Analysis}

Considering the almost magnetic independence and 
structural symmetry, only one pole pitch of one stack of the motor needs to be calculated. Fig. 3 illustrates the no-load magnetic flux density vector distribution. The major path of the PM flux is along one of the PMs - the main air gap - half of the SMC claw pole stator core disk - the stator yoke another half of SMC claw pole stator core disk - main air gap - another PM and then - the mild steel rotor yoke to form a closed loop.

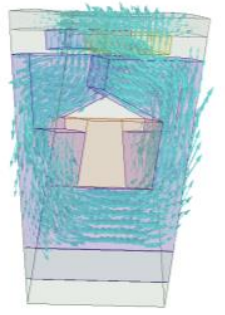

Fig. 3. Plots of magnetic flux density vectors

\section{B. Back EMF}

The flux waveform linking a stator phase winding produced by the rotor PMs can be calculated by rotating the rotor magnets for one pole pitch in steps. When the rotor rotates, the flux linking the stator winding varies and an EMF is induced. In this claw pole PM motor, the flux waveform is almost perfectly sinusoidal versus the rotor position. The induced stator EMF can be determined by:

$$
E=4.44 f N \phi_{m}
$$

where $f$ is the frequency of the induced stator EMF, $N$ the number of turns of the stator winding, and $\emptyset_{m}$ the magnitude of the magnetic flux linking the stator winding. At $1800 \mathrm{rpm}$ $(300 \mathrm{~Hz}), E=48.9 \mathrm{~V}$, and the values of EMF are proportional to rotor speeds.

\section{Winding Inductances}

The behavior of an electrical circuit is governed by the incremental inductance rather than the secant inductance [25]. When considering the non-liner characteristic of the core material, which is the case for changing loading conditions, using the secant inductance to analyze the performance of electrical machines is less reasonable. Since the principle of FEM is based on the minimization of magnetic field energy, choosing energy method i.e. calculating the energy or coenergy stored in all the elements to evaluate inductances is considered as quite accurate. Thus, a modified incremental energy method for calculation of the phase winding incremental inductance of the claw pole motor is used [26]. However, in the case of PM machines, the magnetic field is generated not only by winding currents but also by permanent magnets, and the former one just accounts for a small account. According to the modified incremental energy method, the self-incremental inductance can be computed by:

$$
L(\theta)=2 W_{c}(\Delta i, \theta) /(\Delta i)^{2}
$$

where $W_{c}$ is the magnetic co-energy, $\Delta i$ the current perturbation.

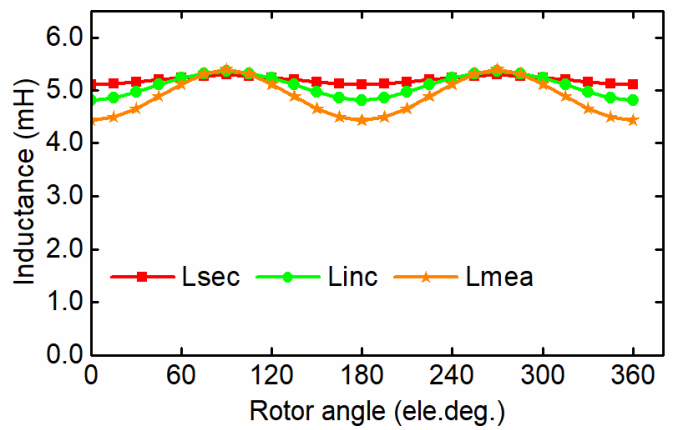

Fig. 4. Self-incremental, secant, and measured inductances

Fig. 4 shows the computed self-incremental inductance as well as the computed secant inductance and measured inductance of one phase winding at different rotor positions. Since the fluctuation of the values of inductances is not significant, for simplification, the phase winding inductance can be considered as a constant, e.g. the average value over a variation cycle. Therefore, the average value of a phase winding's self-inductance can be computed as $L=5.24 \mathrm{mH}$. At the rated operational frequency $300 \mathrm{~Hz}$, the synchronous reactance of the stator winding can be calculated as $X_{s}=2 \pi f_{l} L_{s}=9.88 \Omega$.

\section{Stator Winding Resistance}

The stator winding resistance can be calculated by:

$$
R=\rho l / A
$$

where $l$ is the total wire length, $A$ the wire cross sectional area, and $\rho$ the electrical resistivity of the stator winding.

At the rated winding temperature of $115{ }^{\circ} \mathrm{C}$, representing a temperature rises of $75^{\circ} \mathrm{C}$ above an ambient temperature of 40 ${ }^{\circ} \mathrm{C}$, the resistance is calculated as $0.302 \Omega$.

\section{E. Core Loss Resistance}

As electrical machine rotates, the flux density locus at one position can be alternating (1D), two-dimensional (2D) or even 3D rotating with purely circular or elliptical patterns [27]. In general, the locus, calculated by 3-D magnetic field time-stepping FEM, in each element is an irregular loop in 3D space, while other loops can be seen as special cases of the 3-D loop. Therefore, the core loss in an element can be computed as [27]:

$$
P_{k}=P_{r k} R_{B k}+\left(1-R_{B k}\right)^{2} P_{a k}
$$

where $P_{a k}$ is the alternating core loss, while $P_{r k}$ the circular rotating core loss. $B_{k m a j}$ and $B_{k m i n}$ are the major axes and minor axes of an elliptical flux density loci, and $R_{B k}=B_{k m i n} / B_{k m a j}$.

Furthermore, the total core loss in the SMC core can be computed by [28]: 


$$
P_{t}=\sum_{e=1}^{N_{e}} \sum_{k=0}^{\infty}\left[P_{r k} R_{B k}+\left(1-R_{B k}\right)^{2} P_{a k}\right]
$$

where $N_{\mathrm{e}}$ is the number of elements of the SMC core when performing the magnetic field FEM.

In no-load condition, the calculated core loss based on FEM of the motor at different speeds is illustrated in Table I.

TABLE I

CALCUlated CORE LOSS OF Claw POLE PM Motor

\begin{tabular}{cc}
\hline \hline Speed (rev/min) & Core Loss $(\mathrm{W})$ \\
\hline 300 & 9.7 \\
600 & 18.5 \\
900 & 27.8 \\
1200 & 38.5 \\
1500 & 47.6 \\
1800 & 56.5 \\
\hline
\end{tabular}

The motor is assumed to operate in the optimum brushless DC mode, i.e. $I_{a}$ in phase with $E_{a}$. The test rig of the claw pole PM motor is shown in Fig. 5. A printed circuit disc armature DC machine is connected via a torque transducer as the driver when the prototype is operated as a generator or the load when the prototype is operated as a motor.

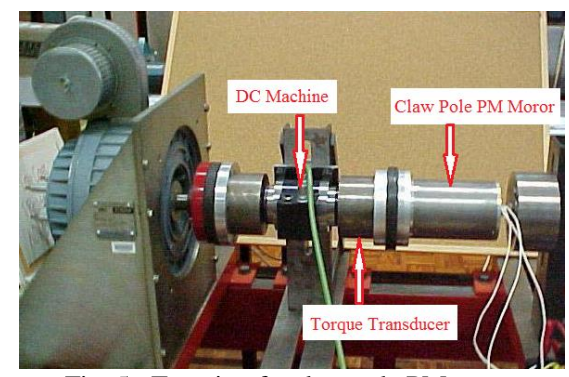

Fig. 5. Test rig of a claw pole PM motor

The core loss can be measured by separating the core loss from the mechanical loss. The calibrated DC motor is used as a prime mover to measure the core loss of the claw pole PM machine. The power feeding the DC motor would be the sum of core loss and mechanical loss (friction and windage) of both the DC motor and the claw pole PM motor. Subtracting the losses of the DC motor yields the core loss and mechanical loss of the claw pole PM motor alone. The mechanical loss of the claw pole PM motor is measured by replacing the stator of the claw pole PM motor with a wooden tube (to imitate the windage), and then repeating the previous test procedure. Therefore, the core loss of the claw pole PM motor is obtained by subtraction of the mechanical loss from the sum of the core loss and mechanical loss. The comparisons between measured core loss and calculated core loss based on FEM at different speeds in no-load steady-state conditions are shown in Fig. 6. The calculated core loss is about $7 \%$ lower than the measured, which may be caused by the measurement error and some addition loss ignored in calculation. The experimental results also suggest the effectiveness of the proposed core loss computation method, and the equivalent core loss resistance identification method based on the above calculation is accurate. The details about how to estimate values of equivalent core loss resistances are shown below.

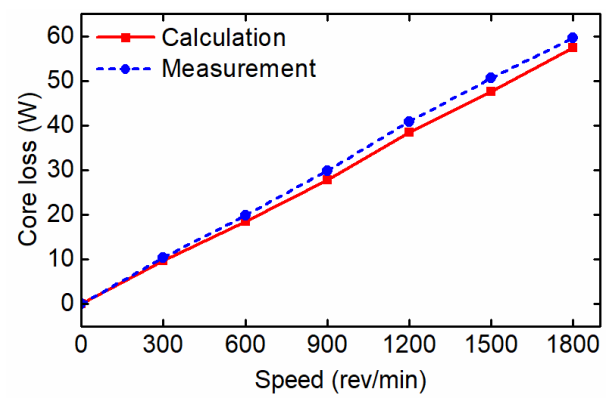

Fig. 6. Core loss measurement and calculation

According to Fig. 2, when the motor operates in no-load condition, $\boldsymbol{I}_{\boldsymbol{a}}$ is considered as zero, then $V_{c}$ and equivalent core loss resistance $R_{c}$ can be calculated as:

$$
\begin{aligned}
V_{c} & =E_{a} \\
R_{c} & =3 V_{c}^{2} / P_{t}
\end{aligned}
$$

where $V_{c}$ is the magnitude of the voltage across the core loss resistance, $P_{t}$ the calculated core loss based on FEM.

The variation of core loss resistance $R_{\mathrm{c}}$ with respect to the motor speed is shown in Fig. 7. It is obvious that the values of $R_{c}$ vary almost in proportional to the rotor speeds (frequencies). This agrees with the dominant hysteresis loss of SMC, which is proportional to the excitation frequency. Then, we can conclude an equation for calculating equivalent core loss resistance by curve-fitting as:

$$
R_{c}=0.0702 n
$$

where $n$ is the rotor speed of claw pole PM motor.

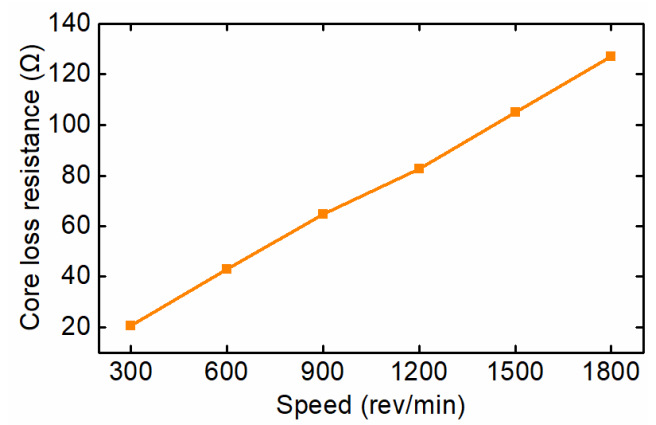

Fig. 7. Core loss resistance $R_{c}$ with respect to motor speed

\section{Performance Analysis Based on The Proposed EQUIVALENT CIRCUIT MODEL}

The motor is assumed to operate in the optimum brushless DC mode, i.e. $\boldsymbol{I}_{\boldsymbol{s}}$ in phase with $\boldsymbol{E}_{\boldsymbol{a}}$, so that the electromagnetic power and torque can be obtained by: 


$$
\begin{gathered}
P_{e m}=3 E_{a} I_{s} \cos \varphi=3 E_{a} I_{s} \\
T_{e m}=P_{e m} / \omega
\end{gathered}
$$

where $\varphi$ is angle between phasors $\boldsymbol{E}_{\boldsymbol{a}}$ and $\boldsymbol{I}_{\boldsymbol{s}}$, and in the optimum brushless DC mode, $\varphi=0$.

In this claw pole PM motor, the electromagnetic torque is a constant in the speed range as: $T_{e m}=0.273 \mathrm{Nm}$.

Since the armature reaction in SMC motor is quite small and it will not demagnetize the magnets, the calculated equivalent core loss resistance $R_{c}$ by (13) can be used to predict core loss in loading conditions, i.e. phase current $I_{a}>0$, then the core loss and copper loss can be predicted by:

$$
\begin{gathered}
\boldsymbol{V}_{\boldsymbol{c}}=\boldsymbol{E}_{\boldsymbol{a}}+\mathrm{j} X_{s} \boldsymbol{I}_{s} \\
P_{\text {core }}=3 V_{c}^{2} / \boldsymbol{R}_{c} \\
\boldsymbol{I}_{\boldsymbol{a}}=\frac{1}{\boldsymbol{R}_{c}} \boldsymbol{E}_{\boldsymbol{a}}+\left(1+\mathrm{j} \frac{X_{s}}{R_{c}}\right) \boldsymbol{I}_{s} \\
\boldsymbol{P}_{\text {copper }}=3 I_{a}{ }^{2} \boldsymbol{R}_{s}
\end{gathered}
$$

where $\boldsymbol{V}_{\boldsymbol{c}}$ is the voltage across the core loss resistance, $\boldsymbol{I}_{\boldsymbol{s}}$ the current through the synchronous inductance, and $\boldsymbol{I}_{\boldsymbol{a}}$ the phase current of claw pole PM motor.

The output power, input power, and efficiency are calculated by:

$$
\begin{gathered}
P_{\text {out }}=P_{\text {em }}-P_{\text {mech }} \\
P_{\text {in }}=P_{\text {em }}+P_{\text {copper }}+P_{\text {core }} \\
\eta=P_{\text {out }} / P_{\text {in }} \times 100 \%
\end{gathered}
$$

where $P_{\text {mech }}$ is the mechanical loss including windage and friction. In this claw pole PM motor, mechanical loss is assumed as $3 \%$ of output power approximately.

The efficiency and output power of the claw pole motor with respect to the percent of rated speed are shown in Fig. 8. The output power is proportional to the percent of rated speed, while the efficiency of motor rises significantly in low speed range and goes up slightly in high speed range, and reaches $85 \%$ at the rated speed.

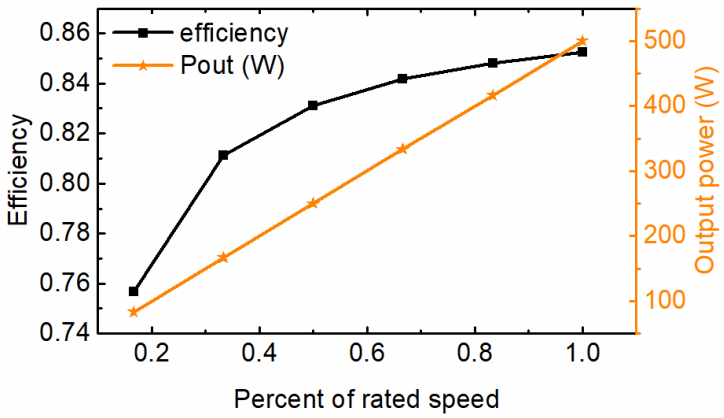

Fig. 8. Efficiency and output power with respect to the percent of rated speed

\section{CONCLUSION}

This paper establishes the equivalent circuit model for predicting core loss in a claw pole PM motor with soft magnetic composite core. All the parameters within the equivalent circuit model including the core loss resistance are determined based on finite element method, which is efficient and accurate, particularly at the design stage. Experimental verification of the core loss of claw pole PM motor has indicated that the proposed parameter identification methods are practical and with good accuracy. Then this circuit model can be used to predict the core loss in both no-load and loading conditions, and the performance analysis has been done for a claw pole PM SMC motor based on the proposed equivalent circuit model. This approach can also be extended to other PM SMC motors.

\section{ACKNOWLEDGMENT}

This work was supported in part by the National Natural Science Foundation of China under Grant No.51677005. Xin $\mathrm{Ba}$ is supported by China Scholarship Council under Grant No. 201706030016.

\section{REFERENCES}

[1] "The latest development in soft magnetic composite technology," SMC Update, Reports of Höganäs AB, Sweden, 1997-2005.

[2] Y. G. Guo, J. G. Zhu, P. A. Watterson, W. M. Holliday, and W. Wu, "Improved design and performance analysis of a claw pole permanent magnet SMC motor with sensorless brushless DC drive," Proc. Fifth Int. Conf. on Power Electronics and Drive Systems, 2003, vol. 1, pp. 704709.

[3] A. G. Jack, B. C. Mecrow, C. P. Maddison, and N. A. Wahab, "Claw pole armature permanent magnet machines exploiting soft iron powder metallurgy," Electric Machines and Drives Conf. Record, 1997, IEEE Int., pp. MA1/5.1 - MA1/5.3.

[4] G. Henneberger and M. Bork, "Development of a transverse flux traction motor in a direct drive system," Proc. Int. Conf. on Electrical Machines, Helsinki, Finland, August 2000, pp. 1457-1460.

[5] Y. G. Guo, J. G. Zhu, P. A. Watterson, and W. Wu, "Development of a permanent magnet transverse flux motor with soft magnetic composite core," IEEE Trans. Energy Conversion, vol. 21, no. 2, pp. 426-434, June 2006.

[6] Y. Chen and P. Pillay, "Axial-flux PM wind generator with a soft magnetic composite core," Industry Applications Conf., 2005. Fourtieth IAS Annual Meeting, vol. 1, pp. 231-237.

[7] A. G. Jack, B. C. Mecrow, and C. P. Maddison, "Combined radial and axial permanent magnet motors using soft magnetic composites," Electrical Machines and Drives, 1999. Ninth Int. Conf. on (Conf. Publ. no. 468), vol. 1, pp. 25-29.

[8] J. Cros, P. Viarouge, Y. Chalifour, and J. Figueroa, "A new structure of universal motor using soft magnetic composites," IEEE Trans. Industry Applications, vol. 40, pp. 550-557, 2004.

[9] A. Jack, B. Mecrow, P. Dickinson, P. Jansson, and L. Hultman, "Design and testing of a universal motor using a soft magnetic composite stator," Industry Applications Conf., 2000. Conf. Record of the 2000 IEEE, vol. 1, pp. 46-50.

[10] S. Okamoto, N. Denis, Y. Kato, M. Ieki, and K. Fujisaki, "Core loss reduction of an interior permanent-magnet synchronous motor using amorphous stator core," IEEE Trans. Industry Applications, vol. 52, no. 3, pp. 2261-2268, 2016.

[11] S. Nandi, "A detailed model of induction machines with saturation extendable for fault analysis," IEEE Trans. Industry Applications, vol. 40, no. 5, pp. 1302-1309, Sep/Oct. 2004.

[12] S. D. Sudhoff, D. C. Aliprantis, B. T. Kuhn, and P. L. Chapman, "An induction machine model for predicting inverter-machine interaction," IEEE Trans. Energy Conversion, vol. 17, no. 2, pp. 203-210, Jun. 2002. 
[13] J. Holtz and T. Thimm, "Identification of the machine parameters in a vector-controlled induction motor drive," IEEE Trans. Industry Applications, vol. 27, no. 6, pp. 1111-1118, Nov/Dec. 1991.

[14] Lu Haifeng, Qu Wenlong, and Huang Bin, "Nonlinear modeling and simulation of induction machine," in 2004 IEEE Region 10 Conf. TENCON 2004. 2004, pp. 507, vol. 3.

[15] E. J. P. E. Subiabre, M. A. Mueller, T. Bertenyi, and T. Young, "Realistic loss modelling and minimisation in an air-cored permanent magnet generator for wind energy applications," in 6th IET Int. Conf. on Power Electronics, Machines and Drives (PEMD 2012), 2012, pp. 1-6.

[16] T. Fukami, T. Hayamizu, Y. Matsui, K. Shima, R. Hanaoka, and S. Takata, "Steady-state analysis of a permanent-magnet-assisted salientpole synchronous generator," IEEE Trans. Energy Conversion, vol. 25, no. 2, pp. 388-393, 2010.

[17] Z. Zhang, Y. Liu, and A. M. Bazzi, "An improved high-performance open-loop V/f control method for induction machines," in 2017 IEEE Applied Power Electronics Conf. and Exposition (APEC), 2017, pp. 615619.

[18] C. A. M. D. Ferraz and C. R. de Souza, "Considering from core losses in modeling the reluctance synchronous motor," in 7th Int. Workshop on Advanced Motion Control. Proceedings (Cat. no.02TH8623), 2002, pp. 251-256.

[19] E. R. Collins, P. B. Boyd, and A. O. Smith, "Improved methods for determining the equivalent circuit parameters for single-phase induction motor models," in Conf. Record of the 1993 IEEE Industry Applications Conf. Twenty-Eighth IAS Annual Meeting, 1993, pp. 397 vol.1.

[20] A. Rabiei, T. Thiringer, and J. Lindberg, "Maximizing the energy efficiency of a PMSM for vehicular applications using an iron loss accounting optimization based on nonlinear programming," in 2012 XXth Int. Conf. on Electrical Machines, 2012, pp. 1001-1007.

[21] Z. M. Zhao, M. Kendig, and D. Rogovin, "Modeling, simulation, and analysis of stator windings of induction machines in high frequencies," in Conf. Record of 1998 IEEE Industry Applications Conf., Thirty-Third IAS Annual Meeting (Cat. no.98CH36242), 1998, pp. 264 vol.1.

[22] F. Fernandez-Bernal, A. Garcia-Cerrada, and R. Faure, "Determination of parameters in interior permanent magnet synchronous motors with iron losses without torque measurement," IEEE Trans. Industry Applications, vol. 37, no. 5, pp. 1265-1272, 2001.

[23] I. Lar and M. M. Radulescu, "Equivalent core-loss resistance identification for interior permanent-magnet synchronous machines," in 2012 XXth Int. Conf. on Electrical Machines, 2012, pp. 1667-1671.

[24] Y. G. Guo, J. G. Zhu, P. A. Watterson, and W. Wu, "Development of a claw pole permanent magnet motor with soft magnetic composite stator," Australian Journal of Electrical \& Electronic Engineering, vol. 2, no. 1, pp. 21-30, 2005.

[25] M. Gyimesi and D. Ostergaard, "Inductance computation by incremental finite element analysis," IEEE Trans. Magn., vol. 35, pp. 1119-1122, 1999.

[26] Y. G. Guo, J. G. Zhu, H. W. Lu, R. Chandru, S. H. Wang, and J. X. Jin, "Determination of winding inductance in a claw pole permanent magnet motor with soft magnetic composite core," in Proc. Australasian Univ. Power Eng. Conf., Hobart, Australia, Sept. 2005, pp. 491-496.

[27] Y. G. Guo, J. G. Zhu, Z. W. Lin, and J. J. Zhong, "Measurement and modeling of core losses of soft magnetic composites under 3D magnetic excitations in rotating motors," IEEE Trans. Magn., vol. 41, no. 10, pp. 3925-3927, Oct. 2005.

[28] Y. G. Guo, J. G. Zhu, H. Y. Lu, Z. W. Lin, and Y. J. Li, "Core loss calculation for soft magnetic composite electrical machines," IEEE Trans. Magn., vol. 48, no. 11, pp. 3112-3115, Nov. 2012. 